\title{
BMJ Open Health and long-term care of the elderly with dementia in rural Thailand: a cross-sectional survey through their caregivers
}

\author{
Nalinee N Chuakhamfoo, ${ }^{1}$ Pudtan Phanthunane, ${ }^{2}$ Sirintorn Chansirikarn, ${ }^{3}$ \\ Supasit Pannarunothai (i) ${ }^{4}$
}

To cite: Chuakhamfoo NN, Phanthunane P, Chansirikarn S, et al. Health and long-term care of the elderly with dementia in rural Thailand: a cross-sectional survey through their caregivers. BMJ Open 2020;10:e032637. doi:10.1136/ bmjopen-2019-032637

- Prepublication history for this paper is available online. To view these files, please visit the journal online (http://dx.doi. org/10.1136/bmjopen-2019032637).

Received 09 July 2019 Revised 22 January 2020 Accepted 25 February 2020

Check for updates

(c) Author(s) (or their employer(s)) 2020. Re-use permitted under CC BY-NC. No commercial re-use. See rights and permissions. Published by BMJ.

${ }^{1}$ Department of Community Medicine, Faculty of Medicine, Naresuan University,

Phitsanulok, Thailand

${ }^{2}$ Department of Economics,

Faculty of Business, Economics and Communications, Naresuan University, Phitsanulok, Thailand ${ }^{3}$ Department of Medicine, Faculty of Medicine Ramathibodi Hospital, Mahidol University,

Bangkok, Thailand

${ }^{4}$ Research unit, Centre for Health Equity Monitoring Foundation, Phitsanulok, Thailand

Correspondence to Dr Supasit Pannarunothai; supasitchem@gmail.com

\section{ABSTRACT}

Objective To describe the circumstances of the elderly with dementia and their caregivers' characteristics in order to examine factors related to activities of daily living (ADL) and household income to propose a long-term care policy for rural areas of Thailand.

Setting A cross-sectional study at the household level in three rural regions of Thailand where there were initiatives relating to community care for people with dementia.

Participants Caregivers of 140 people with dementia were recruited for the study.

\section{Primary and secondary outcome}

measures Socioeconomic characteristics including data from assessment of $A D L$ and instrumental $A D L$ and the Thai version of Resource Utilisation in Dementia were collected. Descriptive statistics were used to explain the characteristics of the elderly with dementia and the caregivers while inferential statistics were used to examine the associations between different factors of elderly patients with dementia with their dependency level and household socioeconomic status.

Results Eighty-six per cent of the dementia caregivers were household informal caregivers as half of them also had to work outside the home. Half of the primary caregivers had no support and no minor caregivers. The elderly with dementia with high dependency levels were found to have a significant association with age, dementia severity, chance of hospitalisation and number of hospitalisations. Though most of these rural samples had low household incomes, the patients in the lower-income households had significantly lower dementia severity, but, with the health benefit coverage had significantly higher chances of hospitalisation.

Conclusion As the informal caregivers are the principal human resources for dementia care and services in rural area, policymakers should consider informal care for the Thai elderly with dementia and promote it as the dominant pattern of dementia care in Thailand.

\section{INTRODUCTION}

A report from $\mathrm{WHO}^{1}$ suggests that dementia is one of the critical causes of dependence and malfunction in old age, as it affects cognitive functions such as memory, logic, awareness and communication. Dementia is one of the
Strengths and limitations of this study

- The present study was among the first crosssectional studies on the burden of dementia in a rural area of an upper-middle-income country.

- The present study recruited only dementia cases with caregivers, most found to be informal caregivers who provided care in addition to other personal responsibilities.

- The present study recommends formal care units to support informal care, especially in rural areas, as the elderly are often dependent on their caregivers.

leading causes of death in old age. ${ }^{2}$ Dementia is not a normal part of old age. There is a misconception that dementia is the regular part of ageing. ${ }^{34}$ Moreover, dementia cannot be avoided or treated causally. ${ }^{5-7}$

It was estimated that there were approximately 600000 elderly people with dementia in Thailand in 2015; this might reach more than a million people by 2030 and 2 million by 2050. This shows that the number of elderly with dementia in Thailand would be 2.4 times the number in Australia, 3.5 times more than in Malaysia and 8.6 times more than in Singapore as shown in figure $1 .^{8}$ Meanwhile, the low birth rate from more than 6 children per woman in 1960 down to about 1.5 children per woman in $2015^{9}$ would have a negative impact on dementia care.

Caring for the elderly with dementia is difficult. ${ }^{1011}$ First and foremost, the caregivers do not necessarily realise that the elderly are struggling with ailing health conditions ${ }^{12}$ as the problems occur in the brain and do not necessarily show obvious physical symptoms. $^{13}$ Caregivers are often faced with irrational behaviours from patients with dementia. Patients with dementia become forgetful. As the illness progresses, other 


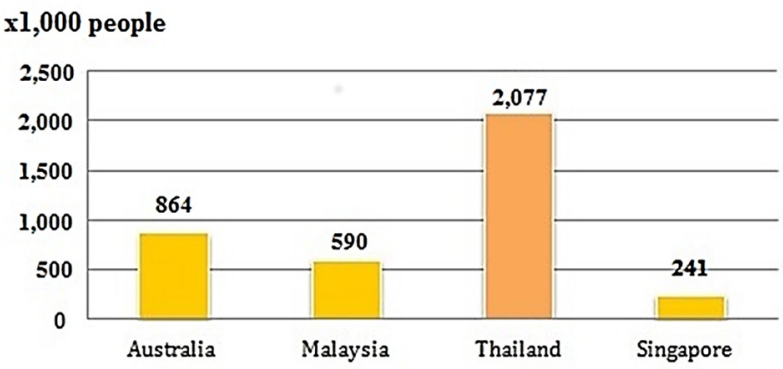

Country

Figure 1 The estimation of the number of people with dementia in $2050 .^{8}$

behaviours can manifest as the patient's cognition functioning declines. ${ }^{14}$

In developed countries, patients with dementia have a higher rate of hospitalisation, for example, $41.9 \%$ in USA, ${ }^{15} 40.8 \%$ in France ${ }^{16}$ and $54.9 \%$ in Japan. ${ }^{17}$ However, the World Alzheimer Report 2015 forecasted that we would find more people with dementia in low-income and middle-income countries, increasing from $58 \%$ of the total number of people with dementia globally in 2015 to $63 \%$ in $2030 .{ }^{18}$ Fotenos et al found a higher risk of dementia in populations with lower socioeconomic status. ${ }^{19}$ However, such dementia studies have never been carried out in Thailand.

In Asia, informal family care plays a significant role in caring for the aged. The person who takes responsibility for dementia care is typically the daughter or daughterin-law since they assume the caretaker's role especially with regard to the tradition of filial piety and familism..$^{20} 21$ The percentage of family caregivers in Thailand, according to a 2014 national health examination survey found that $45 \%$ of caregivers in Thailand were their daughters, $28 \%$ their marriage partners, $18.4 \%$ sons, $6.2 \%$ grandchildren and $2.4 \%$ others. $^{22}$ Most of them are unpaid caregivers. The caregivers are often placed in a circumstance that involves the elderly patient declining mentally, even if they remain physically healthy. ${ }^{23}$ As hidden patients, caregivers increasingly need to use health services. ${ }^{24}$

Since 2005, the number of people aged 60 years and over has been more than $10.7 \%$ of the total population. In 2014, the number of these people was estimated to be $14.9 \% .^{25}$ In 2018, their percentage was estimated to be $17.7 \% .^{26}$ Thailand is now regarded as an aged society. Forecasts suggest that by 2021, the number of people aged 60 years and over will reach $20 \%$. Thailand will be regarded as a super-aged society. ${ }^{27}$ The dependency level increased with age. The elderly aged 80 years and above were $33 \%$ partially dependent and $2 \%$ totally dependent. ${ }^{22}$ The increasing number of elderly is expected to result in an increase in the number of patients with dementia. ${ }^{2}$ However, the circumstances of dementia affect the ageing and the working populations who drive the country's economic development. ${ }^{28}$

The National Health Security Office has been established is to manage the universal coverage scheme (UCS) since 2001. The National Health Security Office introduced development of the community-based longterm care (LTC) strategy during 2014-2016 to broaden the social aspect of health coverage. Also, the second National Elderly Plan (2002-2021) stated that 'the elderly should be entitled to recognition and support by their family, community and the state to the highest dignity, health, and living standards for as long as possible". ${ }^{29}$ This facilitates the integration of community-based LTC with the primary healthcare system. ${ }^{30}$ However, the abovementioned LTC policy focused on general formal care for non-specific chronic diseases which did not specifically fit with dementia care.

Dementia is a specific chronic illness occurring more often with the aged; ${ }^{31}$ care management is much more specific at the dependency level and it differs from other chronic diseases. ${ }^{32}$ As suggested by $\mathrm{WHO},{ }^{33}$ Thailand needs to develop stronger visions and greater coordinated efforts to cope with the burden of dementia like in other countries. The Community Comprehensive Dementia Care was launched by one of the authors (SC) in collaboration with the Ministry of Public Health to provide a pilot community-based dementia care at the household level in selected regions of Thailand through public health personnel. The lesson learnt and experience gained would be forwarded to the Public Health Commission of the National Legislative Assembly. ${ }^{34}$ The present study aims to describe the circumstances of elderly patients with dementia and their caregivers' characteristics in order to examine factors related to activities of daily living (ADL) or dependency level and household income to propose LTC policy for the elderly patients with dementia in rural areas of Thailand.

\section{METHODS}

\section{Study design}

This cross-sectional study gathered information from rural areas where there were Comprehensive Dementia Care initiatives in the community.

\section{Patient and public involvement}

Patients and the public were not involved in the design, planning or the analysis of the study.

Study site

In Thailand, there are no community guidelines for dementia care in the country's LTC system, however, some communities are participating in developing a new model of community dementia care following suggestions by experts in the LTC system. The three areas that joined the Community Comprehensive Dementia Care are Lamsonthi district in Lopburi for the central region, Ban Fang district in Khon Kaen for the north-eastern 


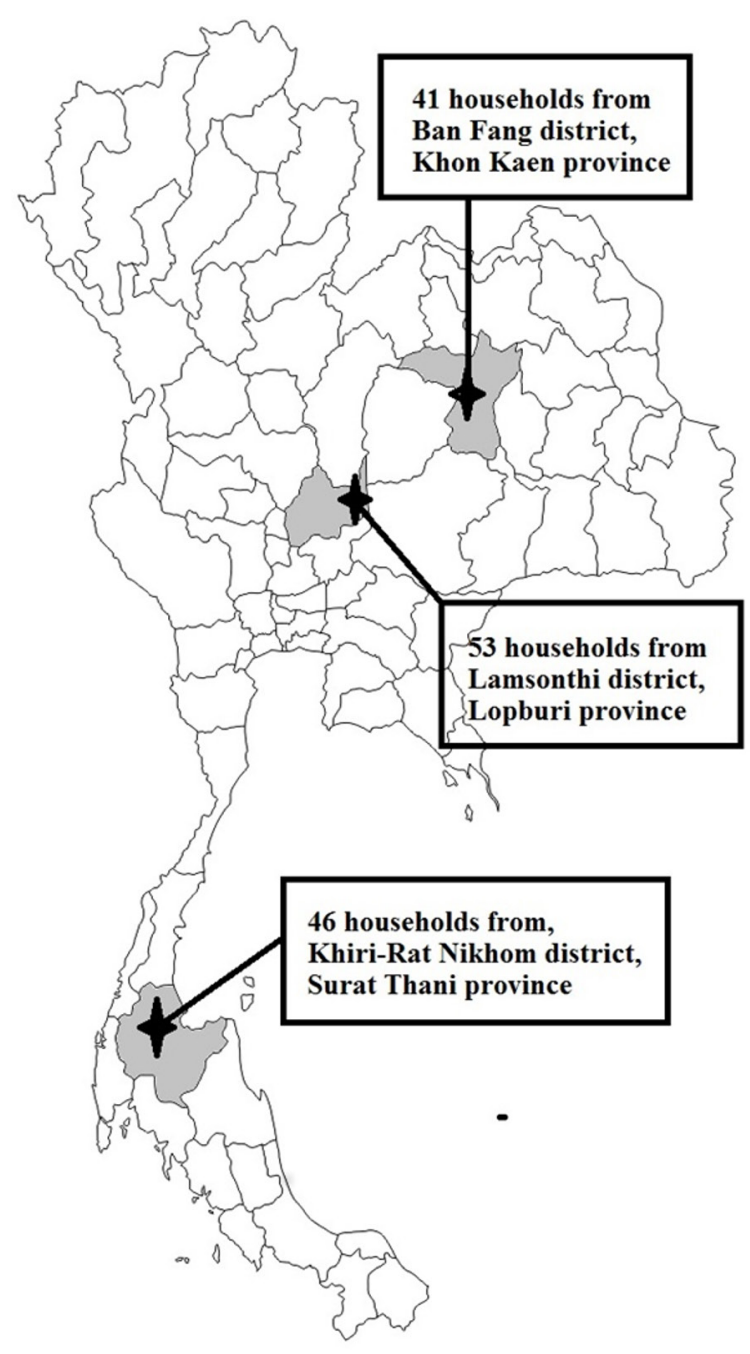

Figure 2 Map of Thailand shows the location of the investigated household participants.

region and Khiri Rat Nikhom district in Surat Thani for the southern region (see figure 2 ).

\section{Diagnosis of dementia}

Persons with dementia in the present study were patients who had been diagnosed by a doctor, who differentiated the severity of their illness into mild, moderate and severe levels.

\section{Population}

The elderly with dementia in the present study included those aged 60 years and above according to the retirement age in Thailand. All patients with dementia in the Community Comprehensive Dementia Care within the three provinces were recruited as target populations of this cross-sectional study. The inclusion criteria were the elderly with dementia who had caregivers that supplied the necessary data regarding their patients and themselves. A non-response rate of $22.2 \%$ of 180 patients was observed because caregivers were not present. In total, there were 50 patients with dementia in Ban Fang, 70 in Lamsonthi and 60 in Khiri Rat Nikhom who were recruited as our study samples. After all of the 140 caregivers understood the study requirements, they agreed to participate by signing a consent form. The researcher (NNG) then interviewed them with structured questionnaires to determine the characteristics of the patient, the caregiver and the circumstances of the dementia care.

\section{Instruments and data collection}

Sociodemographic data of the elderly with dementia and the caregivers

The data collection questionnaire covered general data such as age, sex, education and health coverage schemes; it comprised two parts. The first part included questions on the characteristics of the elderly with dementia, while the second part included questions on the characteristics of the caregiver. Based on Poomontre, ${ }^{35}$ the eight classes of rural households (E, D, C- , C, C+, B, A and A+ based on household asset) were regrouped by the authors of this study into three groups on the basis of household income for accurate statistical analysis. The first level combined $\mathrm{E}$ to $\mathrm{D}$ having a household income of 0-6500 baht per month; the second level was $\mathrm{C}$ - to $\mathrm{C}$ with a household income of 65 001-20 000 baht per month; the third level was $\mathrm{C}+$ to $\mathrm{A}+$ with a household income of 20001 baht per month and higher.

Dependency level: the assessment for ADL and instrumental ADL The ADL and instrumental ADL (IADL) used in this study comprised 16 items with three Likert Scales to assess the capacity of a person to perform an activity of daily life. This version came from the synthesis of the National Health Commission Office of Thailand ${ }^{36}$ as the standard instrument for assessing the quality of clinics for the elderly. Two domains in this instrument measured basic and complex activities. The highest score was 48 , with the score from 16 to 20 being categorised as less dependent, the score from 21 to 35 was categorised as partially dependent, and the score from 36 to 48 categorised as totally dependent. $^{37}$

\section{The Thai version of Resource Utilisation in Dementia}

The present study employed the Thai version of Resource Utilisation in Dementia (RUD) as a tool for investigating the reasons why caregivers took the decision to be dementia carers. The RUD V.3.2 was translated into Thai and back-translated which complied with standard psychometric instrument development by using acceptable validity and reliability test. ${ }^{38}$ The Thai version was used to assess the amount of time given to patients with dementia by their caregivers, and their related characteristics. $^{39} 40$

The researcher contacted health personnel of Community Comprehensive Dementia Care to obtain information on the dementia population in the study areas. Primary data were collected during a $60 \mathrm{~min}$ face-to-face interview at the patient's home or the place of participant's choice. The demographic data of both patients and caregivers were asked. The caregivers were asked about the reasons and circumstances for caring for the 
the elderly with dementia during the past 12 months before the interview in 2017, which included the health services used, such as hospitalisations, outpatient visits to primary healthcare settings and day-care services (home visiting) for both patient and caregiver. The reasons for being informal dementia caregivers were asked. Their health data comprised hours of sleep per day and health services used (hospitalisations, outpatient and home visits). For the health of the elderly with dementia, the researcher asked the caregiver about the dependency level using ADL/IADL items. For the severity of illness, the researcher (NNC) collected the data from the health professional records in each area.

\section{Statistical analysis}

The descriptive statistic was used for the initial analysis. The Kolmogorov statistical test was performed to see whether continuous data were distributed in a normal manner for age, number of family caregivers, caregiver's hours of sleep per day, number of hospitalisations of the patient and of the caregiver. Analysis of variance (ANOVA) was used to explore the relationship between normally distributed variables such as age. For nonnormally distributed variables such as the number of family caregivers, caregiver's hours of sleep per day, the number of hospitalisations for the elderly patients with dementia and the number of caregiver hospitalisations, the Kruskal-Wallis test was used. The $\chi^{2}$ test was performed for the associations of the dependency level of elderly patients with dementia and household income level with gender, dementia severity, health coverage scheme, hospitalisation of elderly patients with dementia and of the caregiver.

\section{Ethical consideration}

To comply with the research ethics consideration focusing on the confidentiality of data, all documents and electronic records were kept in locked storage. All computer files needed a password code to open. No names of people were mentioned in the transcript. The participants gave informed consent before participation in the study. The present study was funded by the Thailand Research Fund (Grant No. PHD/0049/2556). The funder has no control on the publication of research findings.

\section{RESULTS}

Of the total dementia households in the selected areas $77.8 \%$ participated in this study (see figure 3 ). Table 1 shows the characteristics of patients with dementia and their caregivers. There were more female than male patients in every area (a ratio of 1.7:1), and almost threequarters of the caregivers were female. The minimum age of the patients was 60 years and the maximum was 104 years, while of the caregivers was 21 years and 53 years. Most patients and caregivers were covered by UCS (about $85 \%$ ), which became the dominant health benefit ${ }^{41}$ after 2001. Most patients were vulnerable to financial hardship
The selected 3 rural areas from 3 regions of Thailand

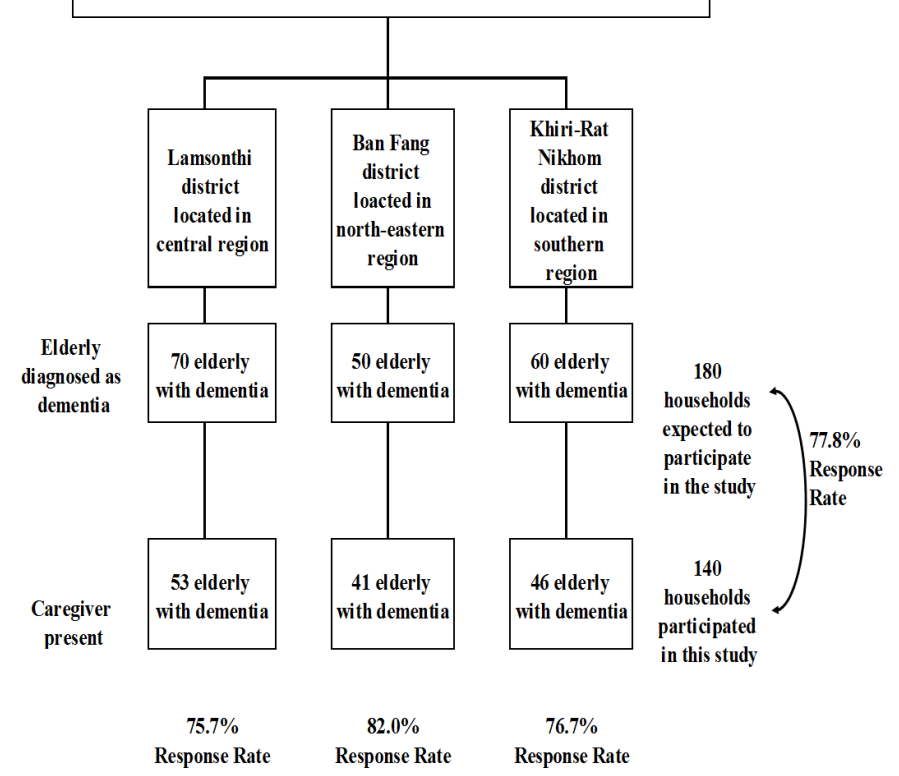

Figure 3 Population and response rate.

due to having income less than 1000 baht (around US\$30) per month. Of the caregivers, only $5.7 \%$ of them reported a monthly income more than 20000 baht (around US\$614).

When focusing on the caregiver's characteristics (see table 2), more than half of them only completed primary school or lower, while $28.3 \%$ of them in the south earned a bachelor's degree or higher, which is significantly different from the $5.7 \%$ of the central, and $9.8 \%$ of the north-eastern region $\left(\chi^{2}(4)=16.86, \mathrm{p}<0.00\right)$. Nearly half $(47 \%)$ of all the caregivers were employed, yet more than half of them in the north-east reported no paid job. The present study found that more than half of the caregivers $(55.7 \%)$ were suffering from health conditions and reported that they had to take medications provided by health professionals. Most of the caregivers $(80 \%)$ had children, and $85 \%$ of them were living with their elderly patients with dementia while half of them reported that they had to take care of their patients without any extra assistance even when they were busy or ill. About $30 \%$ had another person as backup caregiver, while $20.7 \%$ of them reported that they had more than one person to help take care of their patients, and not more than five households in each area ( $7 \%$ of total) were fortunate enough to be able to hire respite care services to relieve the caregiver's burden. The carers were most likely to be the family members, while more than half $(58.6 \%)$ of them were offspring and a quarter of them were the spouse of patients with dementia.

Almost half $(47.9 \%)$ of the caregivers still had other jobs while taking care of their patients (see table 3 ). A fifth of them (20.7\%) reached retirement age, but still had to take care of their patients, because no one else in the household was available to carry out this role. Almost a quarter of them (23.6\%) had to quit their job in order 
Table 1 Characteristics of patients with dementia and caregivers

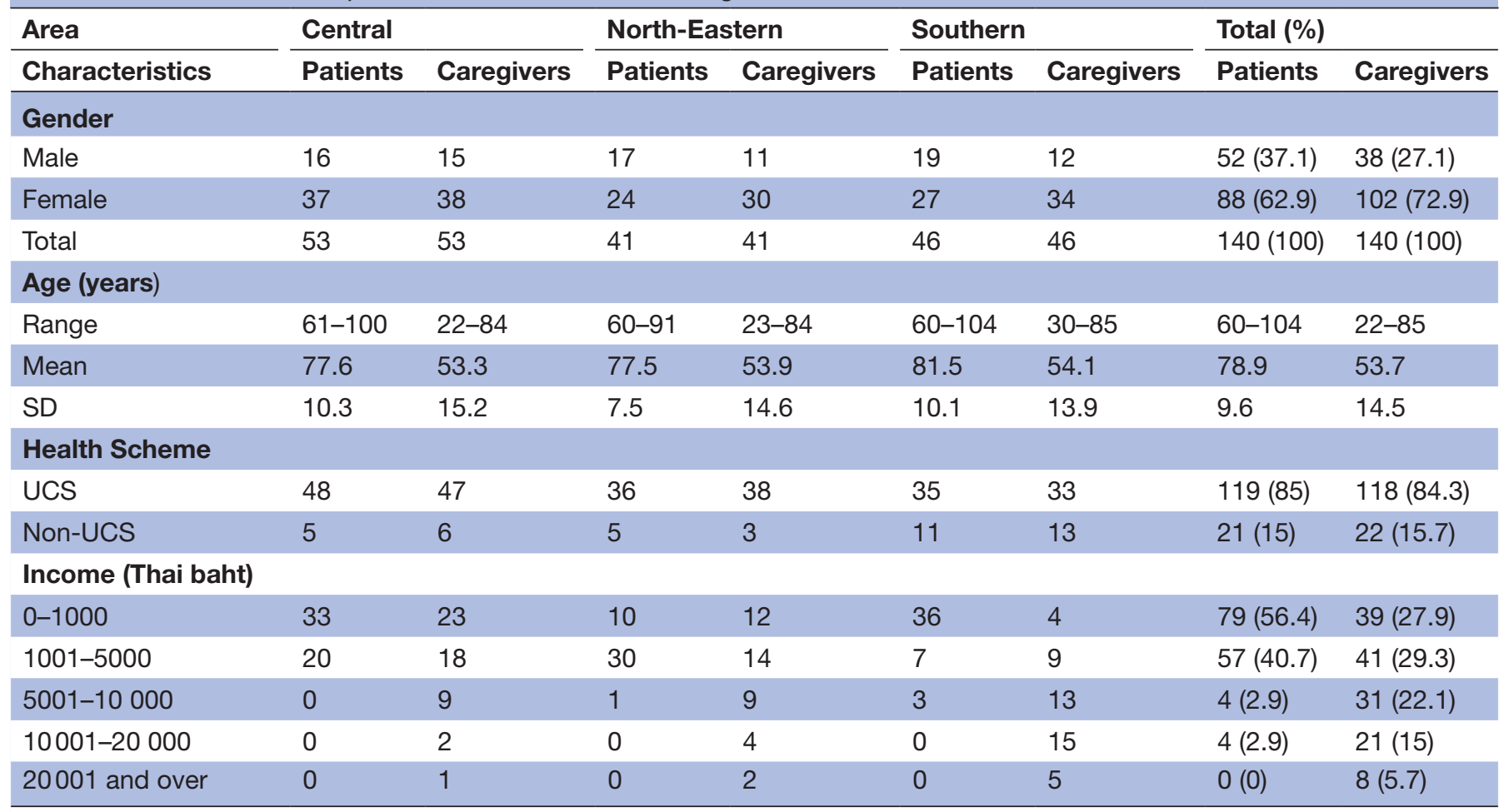

UCS, universal coverage scheme.

to take care of their patients. Some of them had severe health conditions causing them to quit their jobs but still had to take care of their patients. One had been laid-off, and a few had never worked before becoming a caregiver.

To identify factors associated with dependency levels (by ADL/IADL) among people who had dementia, many factors were taken to consideration (see table 4). The mean age of the elderly was statistically different between each level of their dependency (ANOVA F $(2137)=7.77$, $\mathrm{p}<0.00)$. The dependency level also had significant associations with the severity of illness $\left(\chi^{2}(4)=105.38, \mathrm{p}<0.00\right)$; with the chance of hospitalisation of the elderly patient with dementia $\left(\mathrm{X}^{2}(2)=6.46, \mathrm{p}<0.04\right)$; also the frequency of hospitalisation of elderly patient with dementia (KruskalWallis test $\left.\chi^{2}(2)=7.96, \mathrm{p}<0.01\right)$.

Focusing on the household per capita income as socioeconomic status, $48.6 \%$ of them were the poorest, $35.7 \%$ were poor and only $15.7 \%$ had a monthly income of 20001 baht and above. Table 5 presents the factors associated with the level of household income. The income level was significantly associated with dementia severity $\left(\chi^{2}(4)=10.53, \mathrm{p}<0.03\right)$, the health benefit coverage of the elderly with dementia $\left(\mathrm{X}^{2}(4)=12.74, \mathrm{p}<0.01\right)$ and the chance of hospitalisation of the elderly with dementia $\left(\mathrm{X}^{2}(2)=7.09, \mathrm{p}<0.03\right)$.

\section{DISCUSSION}

The main findings of our study provide insight into the issue of the current circumstances of caregivers, patients and formal-informal care in the Thai rural community. The discussions of this study are as follows:

The first concern on informal caregivers is their sandwich generation. More than half of caregivers were the adult children of patients with dementia, and most of these caregivers also had their own offspring. The multigenerational household means that the caregiver could be caught between the needs of the elderly patient and the needs of their own children. ${ }^{42}$ The caregivers are mostly people of working age. ${ }^{43}$ The sandwich generation caregivers have many problems and concerns such as financial difficulties, physical and mental wellness, legal and management issues, and mental health issues. ${ }^{42} 4445$

The next concern is the pattern of an unhealthy lifestyle due to caregiving responsibilities. Despite the absence of statistical significance between the level of dependency and the caregiver's sleep hours per day in this study, one in seven caregivers $(13.6 \%)$ reported that they had unhealthy sleep patterns (less than 6 hours sleep per day). Among these caregivers with low sleep levels, $21.1 \%$ of elderly patients with dementia were less dependent, $36.8 \%$ partially dependent and $42.1 \%$ totally dependent on their caregivers. The finding in table 4 found that the first quartile of the caregiver's hours of sleep was lowest at the partially dependent stage as 6 hours per day. In these circumstances, the caregivers had the lowest numbers of hours of sleep as these patients with dementia were the most active and could exhibit psychotic symptoms before declining to the stage of severe dementia. ${ }^{46}$ Khoo et al ${ }^{47}$ 
Table 2 Characteristics of dementia caregivers

\begin{tabular}{|c|c|c|c|c|}
\hline \multirow[b]{2}{*}{ Area } & \multicolumn{3}{|c|}{ Caregivers $(n=140)$} & \multirow[b]{2}{*}{ Total } \\
\hline & Central & $\begin{array}{l}\text { North- } \\
\text { Eastern }\end{array}$ & Southern & \\
\hline \multicolumn{5}{|l|}{ Educational status } \\
\hline $\begin{array}{l}\text { Primary level and } \\
\text { lower }\end{array}$ & 44 & 28 & 23 & $95(67.9 \%)$ \\
\hline Secondary level & 6 & 9 & 9 & $24(17.1 \%)$ \\
\hline $\begin{array}{l}\text { Bachelor level and } \\
\text { higher }\end{array}$ & 3 & 4 & 14 & $21(15 \%)$ \\
\hline \multicolumn{5}{|l|}{ Employment status } \\
\hline Employed & 27 & 15 & 24 & $66(47.1 \%)$ \\
\hline Unemployed & 26 & 26 & 22 & $74(52.9 \%)$ \\
\hline \multicolumn{5}{|l|}{ Health conditions } \\
\hline $\begin{array}{l}\text { No medications } \\
\text { prescribed }\end{array}$ & 37 & 20 & 23 & $80(57.1 \%)$ \\
\hline $\begin{array}{l}\text { Had medication } \\
\text { prescribed }\end{array}$ & 16 & 21 & 23 & $60(42.9 \%)$ \\
\hline \multicolumn{5}{|l|}{ Caregivers' offspring } \\
\hline Had offspring & 41 & 34 & 37 & $112(80 \%)$ \\
\hline No offspring & 12 & 7 & 9 & $28(20 \%)$ \\
\hline \multicolumn{5}{|c|}{ Relationship with patient } \\
\hline Offspring & 30 & 22 & 30 & $82(58.6 \%)$ \\
\hline Spouse & 15 & 11 & 9 & $35(25 \%)$ \\
\hline Sibling & 1 & 1 & 2 & $4(2.9 \%)$ \\
\hline Others & 7 & 7 & 5 & $19(13.6 \%)$ \\
\hline \multicolumn{5}{|l|}{ Living conditions } \\
\hline Lived with patient & 41 & 38 & 40 & $119(85 \%)$ \\
\hline $\begin{array}{l}\text { Lived in their } \\
\text { household }\end{array}$ & 12 & 3 & 6 & $21(15 \%)$ \\
\hline \multicolumn{5}{|c|}{ Support to caregivers } \\
\hline $\begin{array}{l}\text { No support to } \\
\text { caregivers }\end{array}$ & 29 & 20 & 21 & $70(50 \%)$ \\
\hline $\begin{array}{l}\text { Had one secondary } \\
\text { caregiver }\end{array}$ & 14 & 14 & 13 & $41(29.3 \%)$ \\
\hline $\begin{array}{l}\text { Had more than one } \\
\text { secondary caregiver }\end{array}$ & 10 & 7 & 12 & $29(20.7 \%)$ \\
\hline $\begin{array}{l}\text { Hired respite care } \\
\text { services }\end{array}$ & 3 & 2 & 5 & $10(7.1 \%)$ \\
\hline
\end{tabular}

n, number of participants.

also found that caregiver distress was found the most in cases of moderate dementia. The present study also found higher-income households had significantly shorter caregiver's sleep hours (see table 5), as the higher-income households had greater demand for informal care and greater capacity to support the living issues. The higherincome households delivered more dementia service activities to their elderly, hence reduced caregivers' hours of sleep. During data collection in the present study, the researcher (NNC) observed that the higher-income households also had greater concerns on privacy matters and ignored community support provided by the informal
Table 3 Reasons to be the informal caregiver for the elderly with dementia $(n=140)$

\begin{tabular}{lr}
\hline Reason to be the informal caregiver & $\boldsymbol{N}(\%)$ \\
\hline $\begin{array}{l}\text { No other people to care for the elderly with } \\
\text { dementia but can still be working }\end{array}$ & $67(47.9)$ \\
\hline Reached the age of retirement & $29(20.7)$ \\
\hline $\begin{array}{l}\text { No other people to care for the elderly with } \\
\text { dementia and quit the job }\end{array}$ & $33(23.6)$ \\
\hline $\begin{array}{l}\text { Suffering from own health conditions } \\
\text { Had been laid-off }\end{array}$ & $6(4.3)$ \\
\hline Never worked & $1(0.7)$ \\
\hline Desired to early retired & $3(2.1)$ \\
\hline Total & $1(0.7)$ \\
\hline
\end{tabular}

caregivers while the lower-income households used more of the community support, such as ADL caring services.

Interestingly, the present study found that families with lower incomes are inflicted with the less severe cases of dementia, instead of the higher-income households who face a lower risk of cognitive impairment as the studies conducted in urban areas in the Western countries such as by Fotenos $e t a l^{19}$ and Wee $e t a l^{48}$ Studies were conducted in restricted financial resources but with high piety value. Like in the present study, it was discovered that most highincome households delivered more assistance services with low emotional support for their parents ${ }^{49-51}$ but the low-income households that provided more emotional support with less material assistance ${ }^{52}$ had slowed down cognitive impairment. ${ }^{53}$ The present study suggested further research on whether the opportunity to delay the stages of dementia severity (as found in the high-income group) may be lost if the Thailand dementia care plan did not address the dementia care literacy issue. The benefits would be for all households, rural or urban communities, and higher-income or lower-income households.

While the less severe cases were found more in the lower-income households, higher rates of hospitalisations were found in the lower-income households as shown in table 5. Most of the low-income households' hospitalisations were covered by the UCS and they might see hospitalisation as the option for respite care with no out-of-pocket expenses compared with the higher-income households who could afford the private respite care option.

Despite the high hospitalisation rate of low-income households, the average hospitalisation rate that the present study found at $11.4 \%(16 / 140)$ was comparable with the findings of Liu et $a l,{ }^{54}$ who studied elderly patients with chronic diseases who live in rural areas with low access to healthcare services. The low admission rate found in the present study implies that the ambulatory health services for the patients with dementia at subdistrict health promoting hospitals in rural areas in Thailand were of good quality with a very low co-payment for both ambulatory and hospitalisation services and not a strict gatekeeping rule for hospitalisation. Bodenheimer 
Table 4 Factors associated with the dependency level $(n=140)$

Dementia elderly with Dementia elderly with less dependent $(n=32)$ partially dependent $(n=51)$

\begin{tabular}{|c|c|c|c|c|c|}
\hline & & & & & \\
\hline $\begin{array}{l}\text { Age (years) mean } \\
\text { (range) }\end{array}$ & $75.09(60-100)$ & $77.24(60-104)$ & $82.40(65-98)$ & $7.77 \dagger$ & $0.00^{*}$ \\
\hline Gender & & & & $0.56 \ddagger$ & 0.75 \\
\hline Male n (\%) & $11(34.38)$ & 21 (41.18) & 20 (35.09) & & \\
\hline Female n (\%) & $21(65.63)$ & $30(58.82)$ & 37 (64.91) & & \\
\hline Dementia severity & & & & $105.38 \ddagger$ & $0.00^{*}$ \\
\hline Mild n (\%) & $28(87.5)$ & $21(41.18)$ & $2(2.51)$ & & \\
\hline Moderate n (\%) & $4(12.50)$ & $26(50.98)$ & $11(19.30)$ & & \\
\hline Severe n (\%) & $0(0)$ & $4(7.84)$ & 44 (77.19) & & \\
\hline $\begin{array}{l}\text { Dementia elderly's } \\
\text { health coverage } \\
\text { scheme } \mathrm{n}(\%)\end{array}$ & & & & $3.65 \ddagger$ & 0.72 \\
\hline $\begin{array}{l}\text { Universal coverage } \\
\text { scheme }\end{array}$ & 29 (90.63) & 43 (84.31) & 47 (82.46) & & \\
\hline Social security & $0(0)$ & $1(1.96)$ & $0(0)$ & & \\
\hline $\begin{array}{l}\text { Civil servant medical } \\
\text { benefit }\end{array}$ & $2(6.25)$ & $6(11.76)$ & $9(15.79)$ & & \\
\hline Others & $1(3.13)$ & $1(1.96)$ & $1(1.75)$ & & \\
\hline $\begin{array}{l}\text { Caregiver's health } \\
\text { coverage scheme } \mathrm{n}(\%)\end{array}$ & $45(22.17)$ & $88(43.35)$ & $70(34.48)$ & $3.26 \ddagger$ & 0.78 \\
\hline $\begin{array}{l}\text { Universal coverage } \\
\text { scheme }\end{array}$ & 26 (81.25) & $46(90.20)$ & $46(80.70)$ & & \\
\hline Social security & $2(6.25)$ & $2(3.92)$ & $3(5.26)$ & & \\
\hline $\begin{array}{l}\text { Civil servant medical } \\
\text { benefit }\end{array}$ & $2(6.25)$ & $2(3.92)$ & $6(10.53)$ & & \\
\hline Others & $2(6.25)$ & $1(1.96)$ & $2(3.51)$ & & \\
\hline $\begin{array}{l}\text { Number of informal } \\
\text { caregivers median (Q1- } \\
\text { Q3) }\end{array}$ & $1(0-2)$ & $2(1-2)$ & $2(1-3)$ & $5.0 \S$ & 0.08 \\
\hline $\begin{array}{l}\text { Caregiver's sleep hours } \\
\text { per day (hours) median } \\
\text { (Q1-Q3) }\end{array}$ & $7.5(6.25-9)$ & $8(6-9)$ & $7.5(6.5-8.5)$ & $0.89 \S$ & 0.64 \\
\hline $\begin{array}{l}\text { Whether dementia } \\
\text { elderly had } \\
\text { hospitalisation }\end{array}$ & & & & $6.46 \ddagger$ & $0.04^{*}$ \\
\hline Yes n (\%) & $3(9.38)$ & $2(3.92)$ & $11(19.30)$ & & \\
\hline No n (\%) & 29 (90.63) & $49(96.08)$ & $46(80.70)$ & & \\
\hline $\begin{array}{l}\text { Whether the caregiver } \\
\text { had hospitalisation }\end{array}$ & & & & $4.95 \ddagger$ & 0.08 \\
\hline Yes n (\%) & $2(6.25)$ & $2(3.92)$ & $9(15.79)$ & & \\
\hline No n (\%) & $30(93.75)$ & $49(96.08)$ & $48(84.21)$ & & \\
\hline $\begin{array}{l}\text { Dementia elderly's } \\
\text { number of times of } \\
\text { hospitalisations median } \\
\text { (Q1-Q4) }\end{array}$ & $0(0-5)$ & $0(0-6)$ & $0(0-17)$ & $7.96 \S$ & $0.01^{*}$ \\
\hline & & & & & Continued \\
\hline
\end{tabular}

Continued

Dementia elderly with Test $\quad \mathrm{P}$ totally dependent $(\mathrm{n}=57)$ 
Table 4 Continued

$\begin{array}{llllll}\text { Caregiver's } & 0(0-4) & 0(0-3) & 0(0-30) & 3.58 \S & 0.17\end{array}$

number of times of

hospitalisations median

(Q1-Q4)

${ }^{*} \mathrm{P}<0.05$.

†ANOVA.

$\mp \chi^{2}$.

$\S$ Kruskal-Wallis test.

ANOVA, analysis of variance.

et $a \varphi^{5}$ argued that the primary care system should focus more on the coordination of care than the gatekeeper role. Moreover, the health literacy assessment towards utilisation of health services has to be considered for impending changes in the health systems, as the equity objective of the universal health coverage should reach all populations. ${ }^{56}$
There is a need for informal and formal care coordination. The present study found that the informal caregiver played the significant role of informal care on the elderly with dementia as all of the patients were living in a rural community with their relatives while health professionals provided formal support for both the elderly and the caregiver. Tuppin et $a l^{16}$ agreed that informal

Table 5 Factors associated with the level of household income $(n=140)$

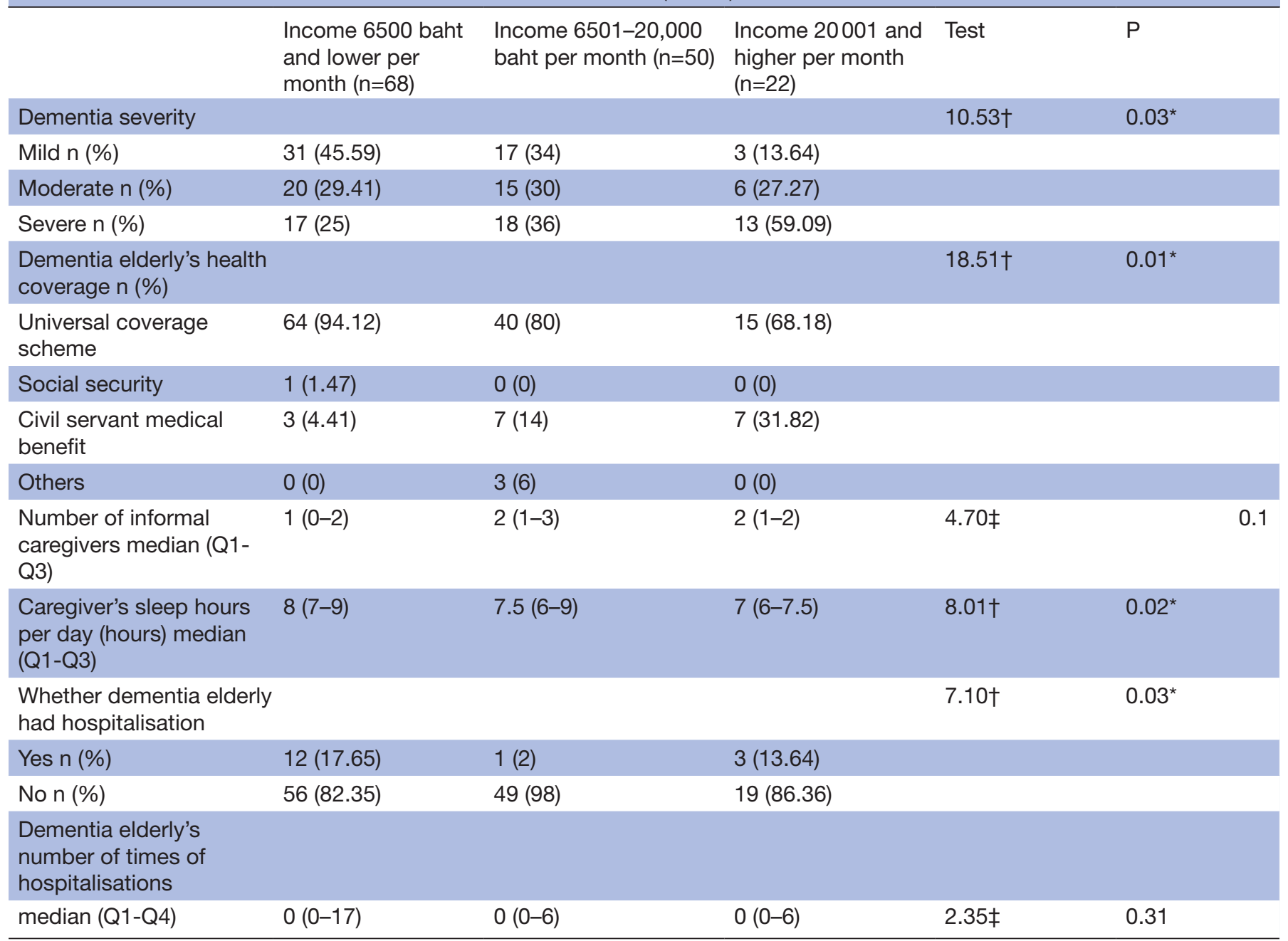

${ }^{*} \mathrm{P}<0.05$.

$+\chi^{2}$.

$\ddagger$ Kruskal-Wallis test.

ANOVA, analysis of variance. 
care complemented formal care, and most patients with dementia relied on informal care. Formal care played an essential role in supporting and guiding efficient informal care as Bremer et $a \tilde{l}^{7}$ found that proper informal caregiving led to lower healthcare spending. Nonetheless, the informal sector needs proper health literacy from the formal sector ${ }^{58}$ and the two systems have to support each other along the way for the best dementia care planning and the management of elderly patients with dementia. The present study found that more than half of the caregivers were unemployed and the caregivers with good health literacy could improve informal dementia care in Thailand. Payment incentives could improve the quality of informal care, as noted in a study by Conrad and Perry. ${ }^{59}$

Implications for policymakers were that they should consider designing both formal and informal care plans in accordance with caregivers' social constraints and their patients' dependency. The multitasked responsibilities, especially in the lowest socioeconomic group found in the present study suggested that the policymakers when improving dementia care in Thailand, should consider informal care for elderly Thai patients and promote it as the dominant pattern of dementia care as the informal caregivers are the principal human resources for dementia care and services in the current circumstances.

\section{Limitations and generalisability: the community is more significant than the household}

This study is probably the first to explore the burden of dementia in rural communities in Thailand. Furthermore, the present study was undertaken in the villages to contribute to the development of the national LTC policy in Thailand.

Of the population of elderly patients with dementia in the present study, $22 \%$ of them were non-responders because caregivers were absent or patients simply lacked caregivers. Most of these non-responders were in the severe level of dementia and in urgent need of sufficient care. The underestimated situations of the present study should be investigated further.

Moreover, the present study investigated circumstances in Community Comprehensive Dementia Care. ${ }^{34}$ Cautions on implications of the findings should be acknowledged. First, as most of the areas of Thailand still lacked a comprehensive dementia care plan, the situations of dementia households might not be the same as these selected areas. Second, different managements of the local governments having different laws ${ }^{60}$ does affect the availability of social services for the elderly with dementia in households. Third, each area in the present study had different geographical and climate issues affecting the population, occupation and income. For example, households in the southern region located in the tropical forest area participating in rubber and coconut agriculture, had a higher income as compared with households in other regions.
Thailand had a strong and highly admired piety value; the strong piety value contributes to the strong belief in Thai society to ostracise those who neglect their sick and elderly. A recent study stated that 'in the moral aspect, the individuals should be responsible for their dependent elderly. If they neglect their duty, they should be penalised with some allegations'. ${ }^{61}$ As it is unacceptable in Thai society, the government shelter home for older persons does not have a popular official name. Another study conducted in the community-based setting revealed that there were many elderly with chronic diseases living in the elderly shelter setting, with no health personnel to take care of. ${ }^{62}$ The present study did not include samples in any older persons' home since there was no such home located in the investigation areas. This study included only the elderly with dementia who had caregivers to give the data.

Even if dementia is an unpreventable and incurable illness ${ }^{2}$ it should be noted that formal health and social sectors in the Thai community had the potential to encourage everyone to practise cognitive skills before anyone in the community is afflicted with dementia. ${ }^{3463}$

\section{CONCLUSION}

The formal health sectors are well established in Thailand, but the informal care circumstances, especially in dementia care, portray a different story. The informal caregivers are the principal human resources for dementia care and services in rural areas; policymakers should consider informal care for the Thai elderly with dementia and promote it as the dominant pattern of dementia care in Thailand. Although, there were factors associated with the dependency levels of the elderly patients with dementia, age, dementia severity, hospitalisations and the frequency of hospitalisations of the elderly had significant associations with the level of dependency. Also, dementia severity, the health benefit scheme of elderly patients with dementia, the caregiver's sleep hours per day and hospitalisation of the patients with dementia had significant associations with their income status. Dementia caregivers in Thailand were mostly family members of patients with dementia, and they are faced with multiple responsibilities.

Contributors All authors conceived the research questions and the concepts of the steps of the study. NNC conducted the field study with caregivers with close guidance from SC. NNC, PP and SP analysed data to answer research questions. All authors have read and agree on the final version of manuscript.

Funding This research is funded by Thailand Research Fund through the Royal Golden Jubilee PhD Program(Grant No. PHD/0049/2556) to Miss Nalinee Nakittipha Chuakhamfoo and Professor Supasit Pannarunothai.

Map disclaimer The depiction of boundaries in this map does not imply the expression of any opinion whatsoever on the part of $B M J$ (or any member of its group) concerning the legal status of any country, territory, jurisdiction or area or of its authorities. This map is provided without any warranty of any kind, either express or implied.

Competing interests None declared.

Patient and public involvement Patients and/or the public were not involved in the design, or conduct, or reporting, or dissemination plans of this research. 
Patient consent for publication Not required.

Ethics approval This cross-sectional study was approved by the Naresuan University Institutional Review Board document number 0251/60.

Provenance and peer review Not commissioned; externally peer reviewed.

Data availability statement Data are available upon reasonable request. Individual data from the survey may be shared under the restricted condition of not exposing confidentiality of the study participants.

Open access This is an open access article distributed in accordance with the Creative Commons Attribution Non Commercial (CC BY-NC 4.0) license, which permits others to distribute, remix, adapt, build upon this work non-commercially, and license their derivative works on different terms, provided the original work is properly cited, appropriate credit is given, any changes made indicated, and the use is non-commercial. See: http://creativecommons.org/licenses/by-nc/4.0/.

\section{ORCID iD}

Supasit Pannarunothai http://orcid.org/0000-0003-3515-1944

\section{REFERENCES}

1 World Health Organization. First WHO ministerial conference on global action against dementia: meeting report; 16-17 March 2015, WHO Headquarters, Geneva, Switzerland, 2015.

2 Alzheimer's Association. 2015 Alzheimer's disease facts and figures. Alzheimers Dement 2015;11:332-84.

3 Lokody I. Beyond art, beyond sciences: the many faces of dementia. Elsevier, 2018.

4 World Health Organization. World report on ageing and health. World Health Organization, 2015.

5 Gräsel E, Wiltfang J, Kornhuber J. Non-Drug therapies for dementia: an overview of the current situation with regard to proof of effectiveness. Dement Geriatr Cogn Disord 2003;15:115-25.

6 Brody JA. An epidemiologist views senile dementia--facts and fragments. Am J Epidemiol 1982;115:155-62.

7 Yaffe K. Modifiable risk factors and prevention of dementia: what is the latest evidence? JAMA Intern Med 2018;178:281-2.

8 Asia Pacific Members of Alzheimer's Disease International, Alzheimer's Australia. Dementia in the Asia Pacific region; the epidemicis here Access Economics; 2014.

9 Woncha-um P, Lefevre AS, Chankaew P. Thailand bets on 'magic pills' to boost declining birth rate. Reuters, 2018.

10 Gillett JE, Crisp DA. Examining coping style and the relationship between stress and subjective well-being in Australia's 'sandwich generation'. Australas J Ageing 2017;36:222-7.

11 Sörensen S, Duberstein P, Gill D, et al. Dementia care: mental health effects, intervention strategies, and clinical implications. Lancet Neurol 2006;5:961-73.

12 Harris J. Recognizing pain and preventing aggression in patients with dementia. Caring for the Ages 2017;18:3.

13 Chenoweth B, Spencer B. Dementia: the experience of family caregivers. Gerontologist 1986;26:267-72.

14 Covinsky KE, Newcomer R, Fox P, et al. Patient and caregiver characteristics associated with depression in caregivers of patients with dementia. J Gen Intern Med 2003;18:1006-14.

15 Phelan EA, Borson S, Grothaus L, et al. Association of incident dementia with hospitalizations. JAMA 2012;307:165-72.

16 Tuppin P, Kusnik-Joinville O, Weill A, et al. Primary health care use and reasons for hospital admissions in dementia patients in France: database study for 2007. Dement Geriatr Cogn Disord 2009;28:225-32.

17 Tadokoro K, Sasaki R, Wakutani Y, et al. Clinical characteristics of patients with dementia in a local emergency clinic in Japan. Geriatr Gerontol Int 2018;18:1383-7.

18 Prince M, Wimo A, Guerchet M. World Alzheimer report 2015. The global impact of dementia. An analysis of prevalence, incidence, cost and trends. London: Alzheimer's Disease International, 2015.

19 Fotenos AF, Mintun MA, Snyder AZ, et al. Brain volume decline in aging: evidence for a relation between socioeconomic status, preclinical Alzheimer disease, and reserve. Arch Neurol 2008;65:113-20.

$20 \mathrm{Kim}$ J-S, Lee E-H. Cultural and noncultural predictors of health outcomes in Korean daughter and daughter-in-law caregivers. Public Health Nurs 2003;20:111-9.

21 Lee J, Sohn BK, Lee H, et al. Impact of behavioral symptoms in dementia patients on depression in daughter and daughter-in-law caregivers. J Womens Health 2017;26:36-43.
22 Aekplakorn W, Pakcharoen H, Sathiennopaklao W, et al. The fifth Thai National health exam survey. Health Systems Research Institute, 2016.

23 Sanders S, Ott CH, Kelber ST, et al. The experience of high levels of grief in caregivers of persons with Alzheimer's disease and related dementia. Death Stud 2008;32:495-523.

24 Roche V, Palmer BF. The hidden patient: addressing the caregiver. Am J Med Sci 2009;337:199-204.

25 National Statistical Office. The 2014 survey of the older persons in Thailand. statistical forecasting bureau national statistical office the government complex, Ratthaprasasanabhakti building. 245. Bangkok, Thailand: Statistical Forecasting Bureau National Statistical Office, 2014.

26 Worldometers.info. Wi team, ed. The Thailand population (live). Worldometers, 2016

$27 \mathrm{Hu} \mathrm{H}-\mathrm{M}$. Facing an aging Society: Taiwan's universities in crisis. Gerontol Geriatr Educ 2018:1-9.

28 Thairath Online. Thailand met an elderly dementia than four hundred thousand people. 18. Thairath, 2015.

29 The National Commission on the Elderly The Ministry of Social Development and Human Security Thailand. The Ministry of Social Development and Human Security Thailand, ed. The 2nd national plan on the elderly 2002-2021. Bangkok: The Ministry of Social Development and Human Security Thailand, 2009.

30 Chuakhamfoo N, Pannarunothai S. Long-term care: choices for Thailand as a middle-income country. J Community Dev Res 2016;9:15-32.

31 Morrison AS. Screening in chronic disease. USA: Oxford University Press, 1992.

32 Aselage MB, Amella EJ. An evolutionary analysis of mealtime difficulties in older adults with dementia. J Clin Nurs 2010;19:33-41.

33 World Health Organization. Dementia: a public health priority. World Health Organization, 2012.

34 The Public Health Commission of the National Legislative Assembly of Thailand. Report of the public health Commission on the consideration of the comprehensive dementia care. Bangkok, Thailand: The Secretariat of the Senate of Thailand, 2018.

35 Poomontre J. Standardization of socio-economic status (Ses) classification in Thailand market research industry. Proceedings of The 2nd Asia Pacific Research Committee Conference (ARPC), 2010.

36 National Health Commission Office of Thailand. The development of long-term care for elderly in Thailand. The 2nd National Health Assembly; 16 Nov 2012, Nonthaburi, 2012.

37 Subcommittee on driving long-term care issues for the elderly National Elderly Committee. The assessment for activities of daily living and instrumental ADL (ADL/IADL); 2012.

38 Chuakhamfoo N, Pannarunothai S, Phantunane P, et al. The validity and reliability of the resource utilization in dementia 3.2 Thai for assessing cost of dementia care. J Community Dev Res 2019;12:1-10.

39 Wimo A, Gustavsson A, Jönsson L, et al. Application of resource utilization in dementia (RUD) instrument in a global setting. Alzheimers Dement 2013;9:429-35.e17.

40 Wimo A, Jonsson L, Zbrozek A. The resource utilization in dementia (RUD) instrument is valid for assessing informal care time in community-living patients with dementia. J Nutr Health Aging 2010;14:685-90.

41 Tangcharoensathien V, Witthayapipopsakul W, Panichkriangkrai W, et al. Health systems development in Thailand: a solid platform for successful implementation of universal health coverage. Lancet 2018;391:1205-23.

42 Burke RJ. 1. The sandwich generation: individual, family, organizational and societal challenges and opportunities. The sandwich generation: caring for Oneself and others at home and at work. 3, 2017.

43 Cheal D. Aging and demographic change. Canadian public Policy/ Analyse de Politiques, 2000: S109-22.

44 Roots CR. The sandwich generation: adult children caring for aging parents. Routledge, 2014.

45 Aazami S, Shamsuddin K, Akmal S. Assessment of Work-Family conflict among women of the sandwich generation. J Adult Develop 2017;25:1-6.

46 Hamuro $\mathrm{A}$, Isono $\mathrm{H}$, Sugai $\mathrm{Y}$, et al. Behavioral and psychological symptoms of dementia in untreated Alzheimer?s disease patients. Psychogeriatrics 2007;7:4-7.

47 Khoo SA, Chen TY, Ang YH, et al. The impact of neuropsychiatric symptoms on caregiver distress and quality of life in persons with dementia in an Asian tertiary hospital memory clinic. Int Psychogeriatr 2013;25:1991-9.

48 Wee LE, Yeo WX, Yang GR, et al. Individual and area level socioeconomic status and its association with cognitive function and 
cognitive impairment (low MMSE) among community-dwelling elderly in Singapore. Dement Geriatr Cogn Dis Extra 2012;2:529-42.

$49 \mathrm{Xie}$ Y, Zhu H. Do sons or daughters give more money to parents in urban China? J Marriage Fam 2009;71:174-86.

50 Lin J. The change trend of intergenerational relations in Taiwan. (In Chinese). Taipei: Taiwan Social Change, Institute of Sociology, Academia Sinica, 2012.

51 Lin J. Intergenerational solidarity between the rural elderly and their adult children. J Taiwan Home Eco 2000;29:32-58

52 Lin J-P, Yi C-C. Filial norms and intergenerational support to aging parents in China and Taiwan. Int J Soc Welf 2011;20:S109-20.

53 Bassuk SS, Glass TA, Berkman LF. Social disengagement and incident cognitive decline in community-dwelling elderly persons. Ann Intern Med 1999;131:165-73.

54 Liu Z, Albanese E, Li S, et al. Chronic disease prevalence and care among the elderly in urban and rural Beijing, China - a 10/66 Dementia Research Group cross-sectional survey. BMC Public Health 2009;9:394.

55 Bodenheimer T, Lo B, Casalino L. Primary care physicians should be coordinators, not gatekeepers. JAMA 1999;281:2045-9.

56 Pannarunothai S, Srithamrongsawat S. Benchmarks of Fairness for health system reform: the tool for national and provincial health development in Thailand. Hum Resour Health Dev J 2000;4:13-26.
57 Bremer P, Challis D, Hallberg IR, et al. Informal and formal care: substitutes or complements in care for people with dementia? empirical evidence for 8 European countries. Health Policy 2017;121:613-22.

58 Ringer TJ, Wong-Pack M, Miller P, et al. Understanding the educational and support needs of informal care-givers of people with dementia attending an outpatient geriatric assessment clinic. Ageing Soc 2020;40:205-28.

59 Conrad DA, Perry L. Quality-based financial incentives in health care: can we improve quality by paying for it? Annu Rev Public Health 2009;30:357-71.

60 Krueathep W. Local government initiatives in Thailand: cases and lessons learned. Asia Pac J Public Adm 2004;26:217-39.

61 Kajornchaikul N. Criminalization on abandon or improperly taking care of dependent elders. Chulalongkorn university, 2016.

62 Knodel J, Chayovan N, Siriboon S. The impact of fertility decline on familial support for the elderly: an illustration from Thailand. Popul Dev Rev 1992;18:79-103.

63 Graff MJL, Vernooij-Dassen MJM, Thijssen M, et al. Community based occupational therapy for patients with dementia and their care givers: randomised controlled trial. BMJ 2006;333:1196. 